\title{
Pendulum Support of the W7-X Plasma Vessel: Design, Tests, Manufacturing, Assembly, Critical Aspects, Status
}

\author{
${ }^{a}$ B. Missal, ${ }^{b}$ F. Leher, ${ }^{b}$ T. Schiller, ${ }^{c}$ P. Friedrich, ${ }^{d}$ A. Capriccioli \\ ${ }^{a}$ Max-Planck-Institut für Plasmaphysik, EURATOM Association, \\ Teilinstitut Greifswald, Wendelsteinstraße 1, D-17491 Greifswald, Germany \\ phone: +49-3834-88-2791, fax: +49-3834-88-2709 \\ ${ }^{b}$ MAN Diesel \& Turbo SE, Werftstraße 17, 94469 Deggendorf, Germany \\ ${ }^{c}$ Universität Rostock, FB Maschinenbau und Schiffstechnik, Albert-Einsteins-Straße 2, 18051 Rostock, Germany \\ ${ }^{d}$ ENEA Frascati, Fusion Technology Unit, Frascati, Italy
}

The superconducting helical advanced stellarator Wendelstein 7-X (W7-X) is under construction at the MaxPlanck-Institut für Plasmaphysik (IPP) in Greifswald, Germany. The three dimensional shape of plasma will be generated by 50 non planar magnetic coils. The plasma vessel geometry follows exactly this three dimensional shape of plasma. To ensure the superconductivity of coils a cryo vacuum has to be generated. Therefore the coils and their support structure are enclosed within the Outer Vessel. Plasma Vessel, Coil structures and Outer Vessel have to be supported separately. This paper will describe the vertical supports of Plasma Vessel which have to fulfill two special requirements, vertical adjustability and horizontal mobility. These two tasks will be carried out by Plasma Vessel Supports (PVS) with hydraulic cylinders, special sliding tables during assembly and pendulum supports during operating phase. The paper will give an overview of design, calculation, tests, fabrication, assembly, critical aspects and status of PVS.

Keywords: Cryostat, Stellarator, Plasma Vessel, Support, Pendulum

\section{Introduction}

The main components of W7-X are the cryostat (Outer Vessel, ports, Plasma Vessel) with the coils and their support structure inside. (Figure 1) All components are supported separately. The paper will describe especially the Plasma Vessel Supports (PVS).

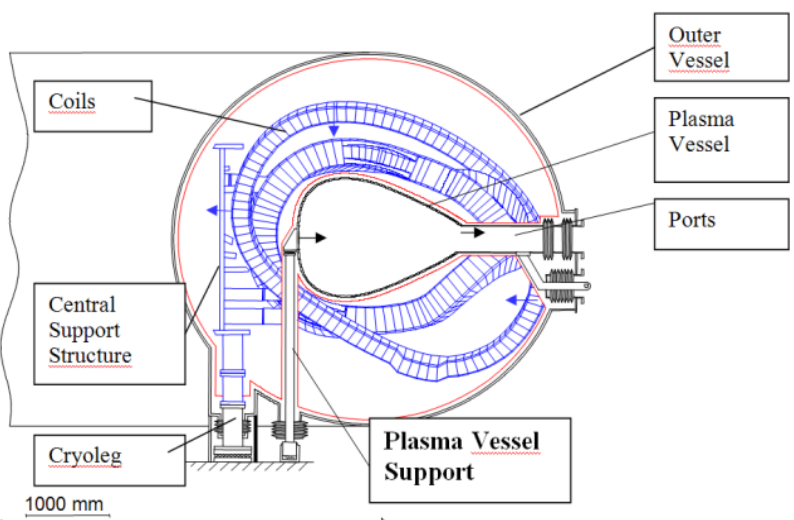

Fig. 1. Schematic cut of cryostat.

\section{Requirements to plasma vessel supports}

The PVS has to fulfill three main requirements: transfer all vertical forces, adjust vertical position and allow horizontal movements (by thermal expansion or active adjustment).

\section{Geometric space and technical requirements}

The PVS are connected outside of the Plasma Vessel between the Coils and break through the shell of the Outer Vessel to the machine base. For installation space generated in a geometric analysis was found: 2 types of
PVS are placed at the inner side and one at the outer side of the Plasma Vessel. (Fig. 2) In summery the Plasma Vessel is formed by 5 modules what means 10 inner and 5 outer supports.

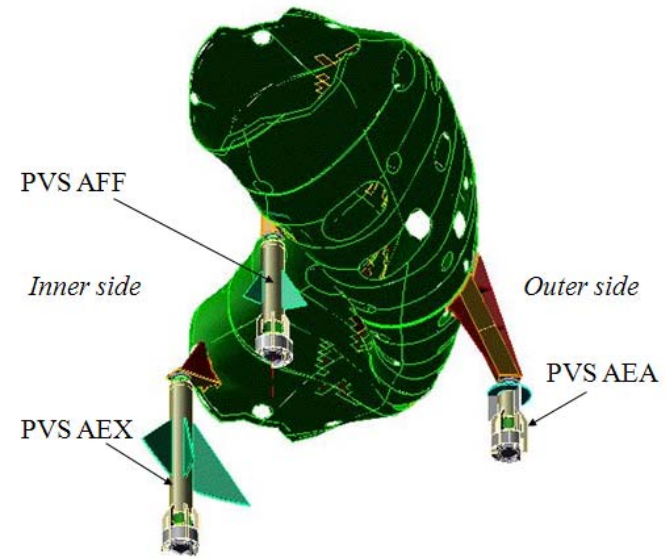

Fig. 2. Plasma Vessel module with vertical supports

Table 1. Technical requirements.

\begin{tabular}{|l|l|l|}
\hline fechnical requirements & value & dimension \\
\hline Max. temperature & +150 & ${ }^{\circ} \mathrm{C}$ \\
\hline Min. temperature & -50 & ${ }^{\circ}$ \\
\hline Max. number of strokes & 1000 & -- \\
\hline Max. vertical stroke & +-10 & $\mathrm{~mm}$ \\
\hline Max. horizontal stroke & $+20-10$ & $\mathrm{~mm}$ \\
\hline Max. Pressure (mside cryostat) & 1.3 & $\mathrm{bar}$ \\
\hline Max. Load/support & 130 & $\mathrm{kN}$ \\
\hline Cobalt content & $<500$ & $\mathrm{ppm}$ \\
\hline Permeability $\mu \mathrm{r}$ & $<1,01$ & -- \\
\hline Material & $\begin{array}{l}1.4429 \\
(316 \mathrm{LN})\end{array}$ & -- \\
\hline
\end{tabular}




\section{History of conceptual design}

\subsection{Planar sliding support}

The first design concept envisaged two concentric tubes, using a hydraulic cylinder at the bottom of the inner tube for vertical adjustment and a commercial planar sliding bearing at the top for horizontal movement (Fig. 3).

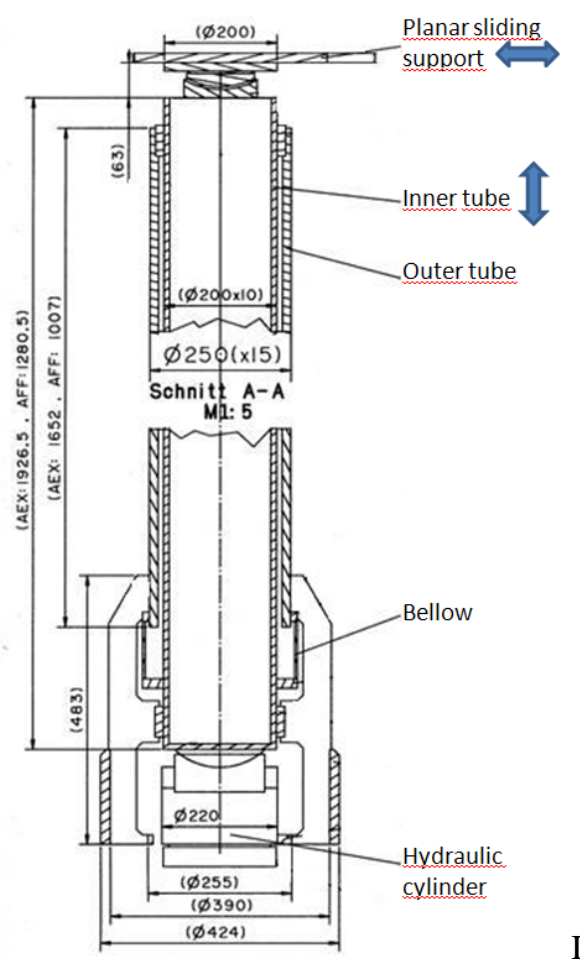

I

Fig. 3. Old variant: Vertical Support (tube in tube) with commercial horizontal sliding bearing.

Simultaneous tests were carried out to check technical values of this bearing type. The test results revealed the following information:

- high resulting horizontal forces (by friction on planar sliding supports) can redound to deformations of plasma vessel and its supports,

- Stick-Slip-Effect can redount to shocks of plasma vessel and its installations,

- the provided material PTFE is not neutron radiation resistant.

Because of these disadvantages it was decided to look for different design solutions.

\subsection{Pendulum support}

The new idea was to fulfill both requirements by using a pendulum (Fig. 4). The new design consists of an additional (third) vertical inner tube with semi-spherical bearings at both ends. The old inner tube is now used for sliding table as described in section six. The semispherical bearing at the bottom is fixed to the hydraulic cylinder, which itself is fixed to the machine foundation. The bearing at the top is free to follow the movements of the Plasma Vessel. The pendulum, formed by the two bearings and the shaft, can withstand all anticipated vertical loads and allows necessary horizontal movements simultaneously (Fig. 5).

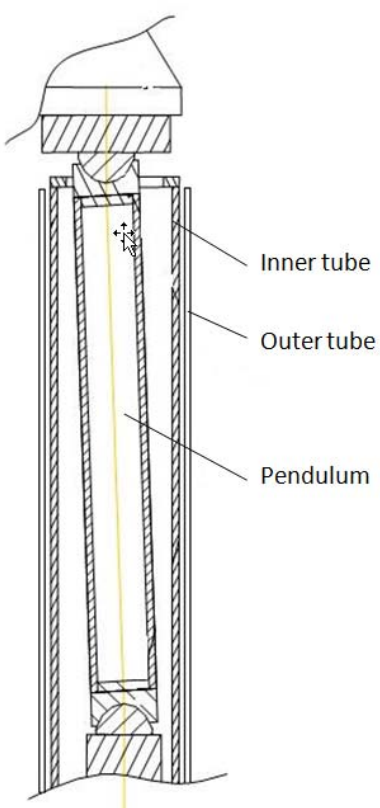

Fig. 4. Schematic view of the pendulum support.

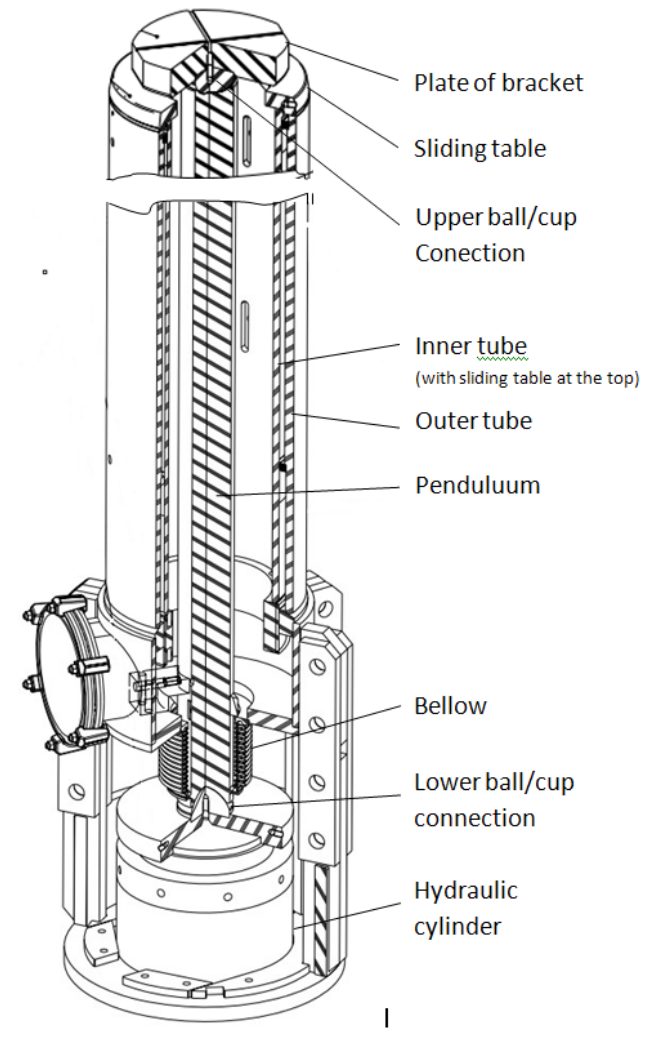

Fig. 5. Design of PVS with pendulum.

Additional horizontal supports (not detailed described in this paper) prevents the pendulums from inadmissible tilting during operation. They consist of threaded bars with hinges between 5 Ports and the Outer Vessel. They enable thermal expansion/horizontal centering and if needful active adjustment of the Plasma Vessel. 


\section{Calculation of Pendulum Support [2]}

Calculations were carried out to ensure that the pendulums fulfill their requirements satisfactorily. Both parameters vary the diameter of the spherical contact surface as well as the length of the connection tube.

If one of these parameters changes, the horizontal reaction forces will also vary. In addition the ratio between the reaction forces and the total vertical loads can be considered as an "Equivalent Plane Sliding" friction factor" (EPSff).

Three pendulum lengths (500, 1000, $2000 \mathrm{~mm})$ and four different diameters of spherical bearings $(70,80$, $100,120 \mathrm{~mm}$ ) were examined in the study. These results represent the "EPSff" (Table 2, Fig. 6). The calculations show lower "EPSff" with longer pendulums (leverage) and smaller sphere diameter (smaller surface).

Table 2 "Equivalent Plane Sliding friction factor" (EPSff) in relation to diameter and length.

\begin{tabular}{|c|c|c|c|}
\hline $\begin{array}{c}\text { Spheres } \\
\text { Diam. }[\mathrm{mm}]\end{array}$ & $\begin{array}{l}\text { Pendulum } \\
\text { Length } \cdots \\
500 \cdot \mathrm{mma}\end{array}$ & $\begin{array}{l}\text { Pendulum } \\
\text { Length } \\
1000 \mathrm{mma}\end{array}$ & $\begin{array}{l}\text { Pendulum } \\
\text { Length } \\
2000 \mathrm{mma}\end{array}$ \\
\hline 70口 & $0.0335 a$ & $0.0167 a$ & $0.0083 a$ \\
\hline 80 口 & $0.0409 a$ & $0.0195 a$ & $0.0098 a$ \\
\hline 100ם & $0.0464 a$ & 0.0 & $0.0117 a$ \\
\hline 120ם & $0.0557 a$ & $0.0276 a$ & $0.0139 a$ \\
\hline
\end{tabular}

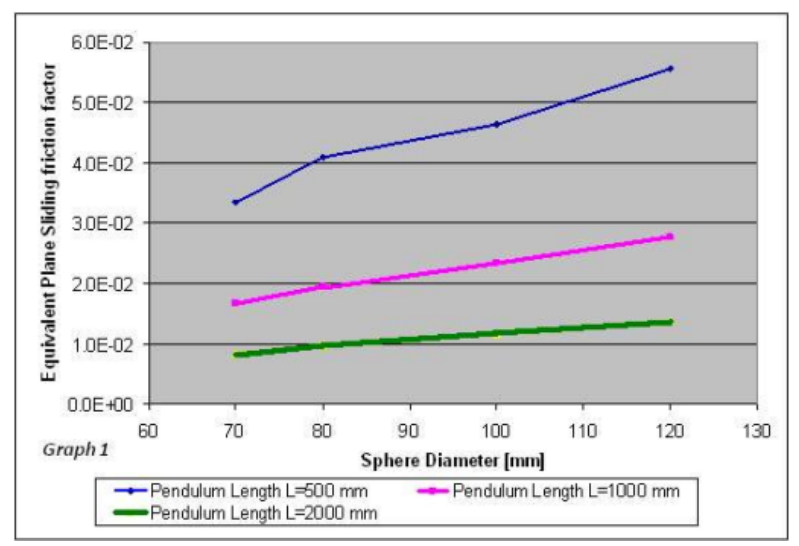

Fig. 6. "Equivalent Plane Sliding" friction factor" (EPSff) in relation to diameter and length.

\section{Detail Design}

For geometric space a diameter of $75 \mathrm{~mm}$ was chosen for both ball/cup. After tests in scale 1:1 the diameter for ball was corrected to $\mathrm{D}=74.7+-0,1$ and for cup to $\mathrm{D}=75.0+$ + 0,1 (chapter seven).

The tube length of the 3 pendulum types is indicated by the geometrical boundary conditions with $1839 \mathrm{~mm}$, $1232 \mathrm{~mm}$ and $608 \mathrm{~mm}$. A hollow tube with an outer diameter of $100 \mathrm{~mm}$ was chosen. It was corrected to solid material of $\mathrm{D}=70 \mathrm{~mm}$ later.

As described in section 4.1 the first design variant applied a commercial planar sliding bearing. It could have been used in both phases:

Assembly phase (horiz. movement because of welding shrinkage) and Operation phase (horiz. movement because of thermal expansion).

With a pendulum the stability during the assembly phase turned out to be insufficient (tilting). An additional separate sliding table was required. The basis of change was the inner tube of the old variant of planar sliding support (chapter 4.1) with a new designed sliding table: inner opening for pendulum and metallic friction with bracket of Plasma Vessel (Fig. 7).

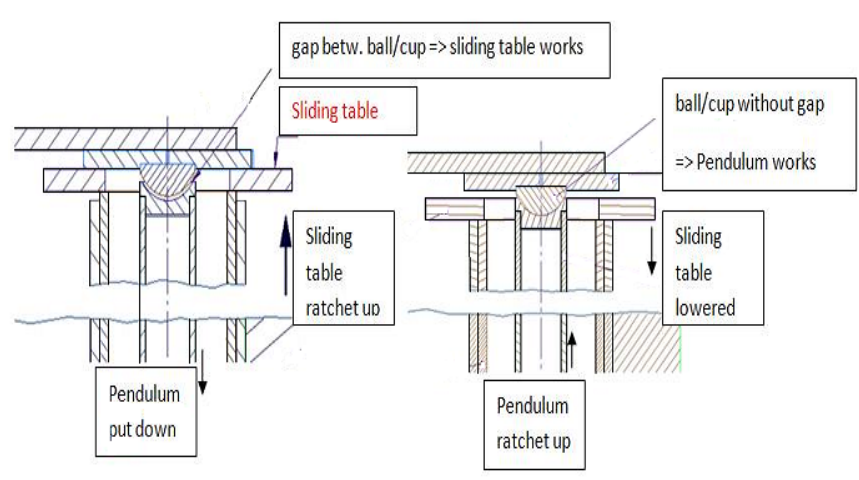

Fig 7. Sliding table works / Pendulum works.

Left hand the jacked sliding table (red) is in contact with bracket of Plasma Vessel (working) and the pendulum has a gap. Right hand the gap of pendulum is closed by raising but the sliding table has a gap.

\section{Tests of pendulum (scale 1:1)}

The next step was to test a 1:1 scale model to select and test the material of the spherical sliding bearing under realistic conditions. The test simulated both, high load $(130 \mathrm{kN})$ and maximum number of strokes (1000). The tests have been performed by the university of Rostock, Germany.

\subsection{Test objectives}

The goals of the tests were to find both an appropriate material and the optimized geometry for the hemisphere bearing that has simultaneously a low frictional coefficient and high fatigue strength.

Therefore the horizontal forces (respective the friction factor) were measured in dependent on a special combination of the length of the pendulum and the kind of material and geometry of the spherical bearing.

For lubrication during real experiment it is planned to use a vacuum compatible molybdenum disulphide, however, it is possible that the lubricant gets lost in operation. For this reason the main tests were carried out without lubricant to simulate the worst case conditions. 


\subsection{Experimental setup}

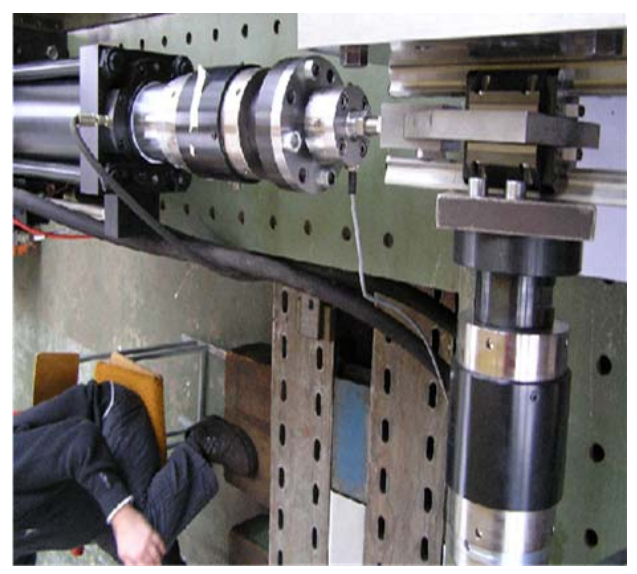

Fig. 8. Original set-up.

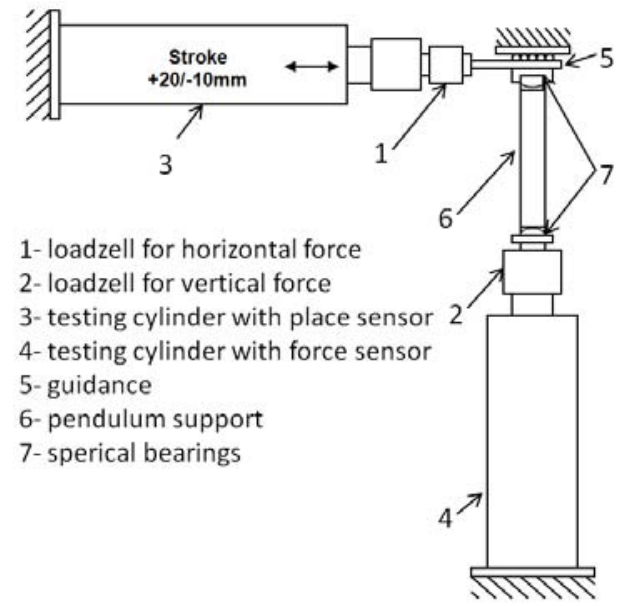

Fig. 9. Principle of test.

For the tests three pendulum supports were manufactured with the original dimensions. A rugged strength frame was used (Fig. 8).

A load of $130 \mathrm{kN}$ was applied by a hydraulic cylinder (detail 4 in Fig. 9).

A load cell (detail 2) was used to monitor the vertical force constantly.

As the plasma vessel can shrink by $10 \mathrm{~mm}$ and extend by $20 \mathrm{~mm}$ during the different operating modes a second hydraulic cylinder (detail 3) was installed. This hydraulic cylinder produced a specific displacement and the required force for those movements was measured with a load cell (detail 1).

The rolling resistance of the roller bearing (detail 5) was determined in a pre-test to be negligible.

\subsection{Testing procedure and results}

After each test campaign the obtained data were compared with the target values. Afterwards modifications were made for the subsequent campaigns.

\section{Pre-Tests (Test campaign 1-12)}

At first a series of pre-tests was performed to test the system. Pre-tests were performed on three pendulum supports of different lengths, each for two different loads. In each of these test campaigns only ten strokes with/ without lubricated bearings were realized.

The pre-tests confirmed the functionality of the test system. As expected the tests ensure that the horizontal forces were higher with shorter pendulums and without lubricant.

\section{Short unlubricated pendulum (Test 13)}

The shortest support was used (because of the highest equivalent friction factor) in the non-lubricated state (worst case). The force was measured and recorded after 5, 10, 20, 40, 60, 80 and 100 strokes (Fig. 10, Fig. 11).

It was detected that the forces were very high and the abrasion was not acceptable. Therefore more tests with different tolerances and ball materials were performed.

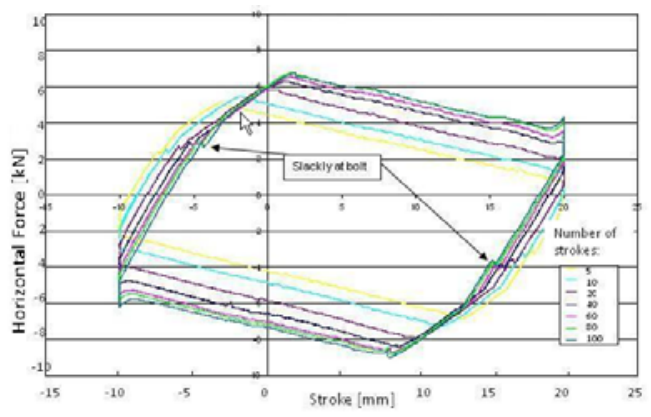

Fig. 10. Test 13/ horizontal Forces/ strokes.

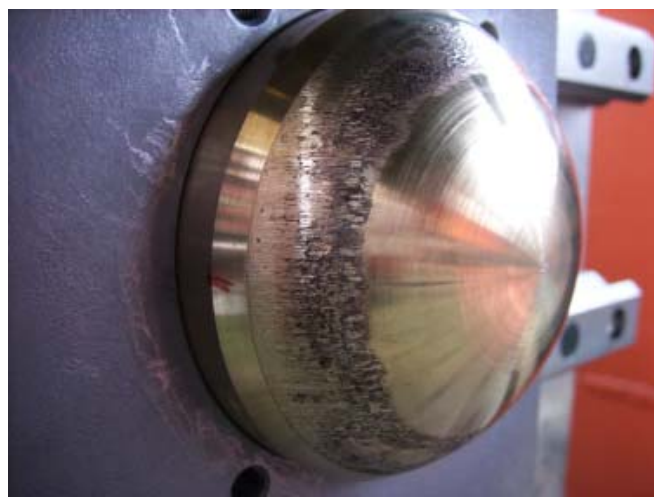

Fig. 11. Test 13/ ball after 100 strokes

\section{Unsuccessful modification trials (Tests 14-17)}

All following tests were unsuccessful because of stick-slip effects. Therefore they were stopped before completion of 1000 strokes.

\section{First successful design (Test 18)}

Stainless steel 1.4429 with additional special hardening was used for the cup. The ball was manufactured from laser smelted material. In this test 1000 strokes were accomplished with reduced abrasion and no stick-slip effects.

Unfortunately the effort (time, cost) for laser smelting and hardening was too high and abrasion was reduced but significant. So it was decided to look for a less work intensive solution. 


\section{Improved design (Test 19)}

The cup material 1.4429 was used again, but not hardened. For the ball the new material CC496K was used. This ball material is a lead-bronze alloy with a lead content of $15 \%$. The gain of this material is that it is self-lubricating and vacuum compatible.

The reduced strength at higher temperatures could be an issue for this material, but in this application (max. $120^{\circ} \mathrm{C}$ ) it is sufficient. The results of this test were (Fig. 12, 13): no stick slip, lowest equivalent friction factor and lowest abrasion.

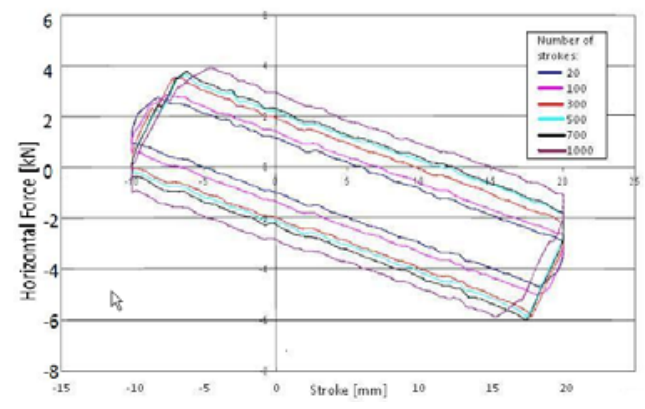

Fig. 12. Test 19/ horizontal forces/ strokes.

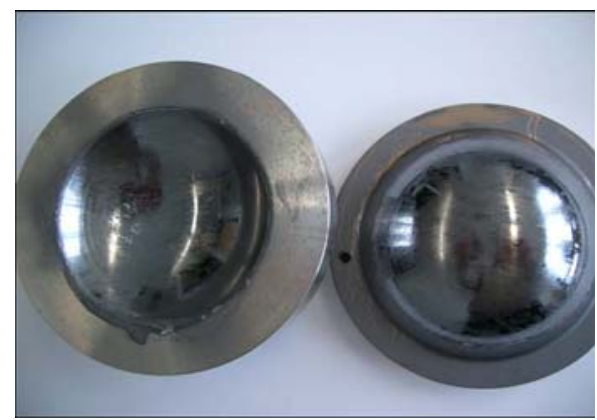

Fig. 13. Test 19/ ball and cup after 1000 strokes.

Because of these very positive results it was decided to finish the tests and use this material combination (cup material 1.4429 and ball material CC496K) for all Plasma Vessel Supports in W7-X.

A detailed description of the test results can be found in [3]. After the successful verification of the working principle and clarification of material the fabrication was released.

\section{Manufacturing}

MAN-DT (Germany) was the manufacturer.

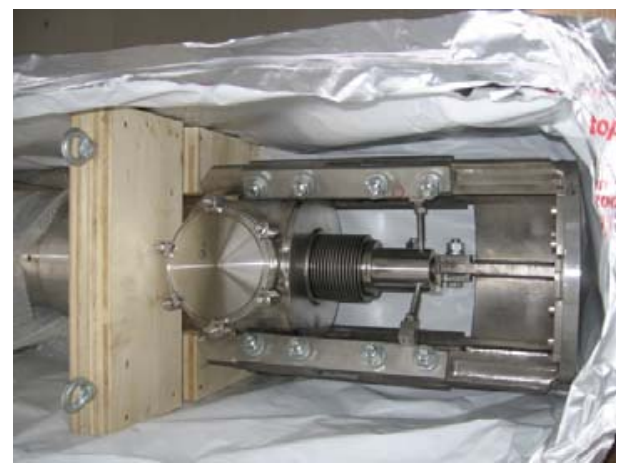

Fig. 14. One PVS before shipping.
The collaboration is very successful, as all work was carried on time and met the required quality control and management goals. Figure 14 shows a PVS after manufacturing.

\section{Assembly of Pendulum Supports}

The assembly of Pendulum Supports was the last challenging step because of the required horizontal accuracy of $+-3 \mathrm{~mm}$ at the top of PVS.

Especially the shrinkage of the welds at the bottom (to the Outer Vessel shell) could have a considerable influence on the positioning accuracy of the top because of leverage effect.

Therefore the positions of the tops were measured continuously with laser tracker during the welding. As a result the required accuracy was reached with $+-2 \mathrm{~mm}$ and the tests of welding seams were successful. (Fig. 15)

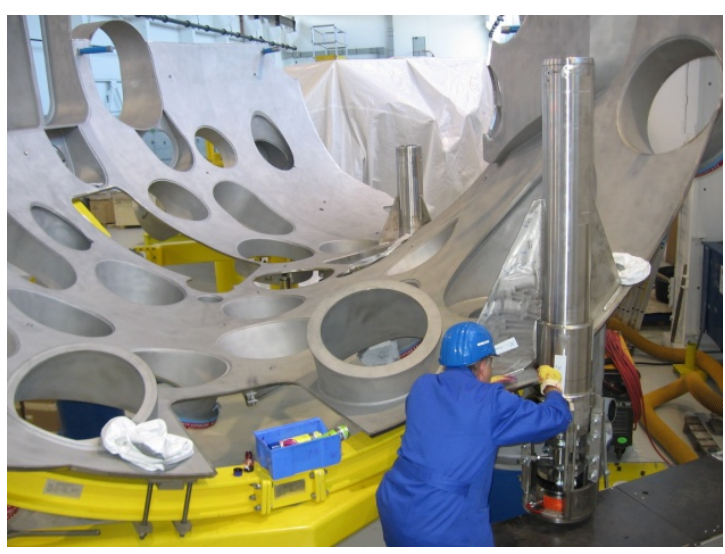

Fig. 15. PVS during penetration test.

\section{Summary}

First design solutions for PVS showed disadvantages. Hence the calculations and tests were carried out and the design was optimised, so this component shall ensure to be reliably part of the whole experiment W7-X.

\section{References}

[1] B. Missal; Mechanical Experiments about Pendulum Support of Vacuum Vessel W7-X, Fusion Engineering and Design, Volume 83, issues 10-12 (2008) 1610-1613.

[2] A. Capriccioli; Plasma Vessel vertical supports Pendulum solution; Equivalent Friction Factor Calculation; 1ABH00H-T0004.0 (intern IPP).

[3] P. Friedrich, 1:1-Tests von Pendelstützen für die vertikale Abstützung des Plasmagefäßes des Wendelstein 7-X Experimentes, final report, IPP document no. 1-ABH00V-T2005.2, 2007 (intern IPP). 